\title{
Movimento Negro Brasileiro: alguns apontamentos históricos*
}

\author{
Petrônio Domingues**
}

A finalidade deste artigo é fazer alguns apontamentos acerca de um tema subexplorado na historiografia brasileira: a trajetória do movimento negro organizado durante a República (1889-2000), com as etapas, os atores e suas propostas. A idéia central é demonstrar que, em todo o período republicano, esse movimento vem desenvolvendo diversas estratégias de luta pela inclusão social do negro e superação do racismo na sociedade brasileira.

Palavras-chave: População Negra - Anti-racismo - Movimento Negro

\section{The Brazilian Black Movement: Some Historical Notes}

The present article comments upon an under-explored subject in Brazilian historiography: the trajectory of that country's organized Black movement during the Republican period (1889-2000). Our main objective is to demonstrate that, throughout the period in question, the Black movement developed a series of different strategies in the struggle against racism and in favor of the social inclusion of the Black people in Brazilian society.

Keywords: Black people - Anti-racism - Black Movement

Le mouvement noir brésilien : quelques notes historiques

Cet article traite d'un sujet peu exploré par l'historiographie : la trajectoire du mouvement noir organisé au Brésil pendant la République (1889-2000). L'idée centrale est

* Artigo recebido em abril de 2006 e aprovado para publicação em março de 2007.

** Doutor em História pela Universidade de São Paulo. Professor da Universidade Estadual do Oeste do Paraná (Unioeste). E-mail: petronio@usp.br. 
de démontrer que, durant toute la période républicaine, ce mouvement a développé plusieurs stratégies de lutte pour l'inclusion sociale des noirs afin de surmonter le racisme dans la société brésilienne.

Mots-clés: Population Noire - Antiracisme - Mouvement Noir

\section{Introdução}

A finalidade deste artigo é fazer alguns apontamentos acerca de um tema subexplorado na historiografia brasileira: a trajetória do movimento negro organizado durante a República (1889-2000), com as etapas, os atores e suas propostas. Para tanto, amparar-se-á, preferencialmente, na produção intelectual das lideranças negras (José Correia Leite, Francisco Lucrécio, Abdias do Nascimento, Hamilton Cardoso, Lélia Gonzalez, dentre outras), por meio de depoimentos, memórias e textos ensaísticos. A idéia central é demonstrar que, em todo o período republicano, esse movimento vem empreendendo, dinamicamente, diversas estratégias de luta a favor da população negra.

A partir das reflexões de Ilse Scherer-Warren, pode-se caracterizar movimento social como um "grupo mais ou menos organizado, sob uma liderança determinada ou não; possuindo programa, objetivos ou plano comum; baseando-se numa mesma doutrina, princípios valorativos ou ideologia; visando um fim específico ou uma mudança social". ${ }^{1}$ Mas, nesse cenário, como pode ser definido movimento negro? Movimento negro é a luta dos negros na perspectiva de resolver seus problemas na sociedade abrangente, em particular os provenientes dos preconceitos e das discriminações raciais, que os marginalizam no mercado de trabalho, no sistema educacional, político, social e cultural. ${ }^{2}$ Para o movimento negro, a "raça", ${ }^{3}$ e, por conseguinte, a identida-

\footnotetext{
${ }^{1}$ Ilse Scherer-Warren, Movimentos sociais: um ensaio de interpretação sociológica, 2.ed., Florianópolis, Ed. da UFSC, 1987, p. 13.

${ }^{2}$ Cf. Regina Pahim Pinto, O movimento negro em São Paulo: luta e identidade, São Paulo, Tese de Doutorado, FFLCH-USP, 1993.

${ }^{3} \mathrm{O}$ conceito de raça é definido como uma construção social, com pouca ou nenhuma base biológica. A raça é importante porque as pessoas classificam e tratam o "outro" de acordo com as idéias socialmente aceitas. Referenda-se, aqui, a posição de Edward Telles: "o uso do termo raça fortalece distinções sociais que não possuem qualquer valor biológico, mas a raça continua a ser imensamente importante nas interações sociológicas e, portanto, deve ser levada em conta nas análises sociológicas [e históricas]”. Cf. Edward Telles, Racismo à brasileira: uma nova perspectiva sociológica, Rio de Janeiro, Relume Dumará-Fundação Ford, 2003, p. 38.
} 
de racial, é utilizada não só como elemento de mobilização, mas também de mediação das reivindicações políticas. Em outras palavras, para o movimento negro, a "raça" é o fator determinante de organização dos negros em torno de um projeto comum de ação.

Outra definição de movimento negro é aquela atribuída por Joel Rufino dos Santos, compreendendo

(...) todas as entidades, de qualquer natureza, e todas as ações, de qualquer tempo [aí compreendidas mesmo aquelas que visavam à autodefesa física e cultural do negro], fundadas e promovidas por pretos e negros (...). Entidades religiosas [como terreiros de candomblé, por exemplo], assistenciais [como as confrarias coloniais], recreativas [como "clubes de negros"], artísticas [como os inúmeros grupos de dança, capoeira, teatro, poesia], culturais [como os diversos "centros de pesquisa"] e políticas [como o Movimento Negro Unificado]; e ações de mobilização política, de protesto anti-discriminatório, de aquilombamento, de rebeldia armada, de movimentos artísticos, literários e 'folclóricos' - toda essa complexa dinâmica, ostensiva ou encoberta, extemporânea ou cotidiana, constitui movimento negro. ${ }^{4}$

Contudo, esta definição de Rufino dos Santos só faz sentido do ponto de vista militante, pois ela é, no mínimo, problemática em uma abordagem historiográfica. Se se consideram como movimento negro todos os movimentos que organizem em qualquer tempo e aspecto sob qualquer rubrica descendentes de africanos no Brasil, neste artigo estariam faltando, entre outros temas, a história das irmandades negras, dos terreiros de candomblé, da capoeira ou das escolas de samba. É de movimento político de mobilização racial (negra) que será tratado aqui, mesmo que este movimento assuma em muitos momentos uma face fundamentalmente cultural.

\section{Primeira fase do Movimento Negro organizado na República (1889-1937): da Primeira República ao Estado Novo}

Um ano após a abolição da escravatura, foi proclamada a República no Brasil, em 1889. O novo sistema político, entretanto, não assegurou profícuos ganhos materiais ou simbólicos para a população negra. Ao contrário, esta, segundo Andrews, foi marginalizada,

\footnotetext{
${ }^{4}$ Joel Rufino dos Santos, "Movimento negro e crise brasileira", Atrás do muro da noite; dinâmica das culturas afro-brasileiras, Joel Rufino dos Santos e Wilson do Nascimento Barbosa, Brasília, Ministério da Cultura/Fundação Cultural Palmares, 1994, p. 157.
} 
seja politicamente em decorrência das limitações da República no que se refere ao sufrágio e as outras formas de participação política; seja social e psicologicamente, em face das doutrinas do racismo científico e da "teoria do branqueamento"; seja ainda economicamente, devido às preferências em termos de emprego em favor dos imigrantes europeus. ${ }^{5}$

Para reverter esse quadro de marginalização no alvorecer da República, os libertos, ex-escravos e seus descendentes instituíram os movimentos de mobilização racial negra no Brasil, criando inicialmente dezenas de grupos (grêmios, clubes ou associações) em alguns estados da nação.

Em São Paulo, apareceram o Club 13 de Maio dos Homens Pretos (1902), o Centro Literário dos Homens de Cor (1903), a Sociedade Propugnadora 13 de Maio (1906), o Centro Cultural Henrique Dias (1908), a Sociedade União Cívica dos Homens de Cor (1915), a Associação Protetora dos Brasileiros Pretos (1917); no Rio de Janeiro, o Centro da Federação dos Homens de Cor; ${ }^{6}$ em Pelotas/ RG, a Sociedade Progresso da Raça Africana (1891); em Lages/SC, o Centro Cívico Cruz e Souza (1918). ${ }^{7}$ Em São Paulo, a agremiação negra mais antiga desse período foi o Clube 28 de Setembro, constituído em 1897. As maiores delas foram o Grupo Dramático e Recreativo Kosmos e o Centro Cívico Palmares, fundados em 1908 e 1926, respectivamente. De cunho eminentemente assistencialista, recreativo e/ou cultural, as associações negras conseguiam agregar um número não desprezível de "homens de cor", como se dizia na época. Algumas delas tiveram como base de formação "determinadas classes de trabalhadores negros, tais como: portuários, ferroviários e ensacadores, constituindo uma espécie de entidade sindical" ${ }^{8}$ Pinto computou a existência de

\footnotetext{
${ }^{5}$ George Reid Andrews, “O protesto político negro em São Paulo (1888-1988)”, Estudos AfroAsiáticos, n. 21, Rio de Janeiro, 1991, p. 32.

${ }^{6}$ Em São Paulo, também surgiu um Centro da Federação dos Homens de Cor, em 1914, o que permite supor que essa entidade e aquela existente no Rio de Janeiro eram a mesma. Se essa suposição for confirmada, tratava-se da primeira entidade negra do país de abrangência interestadual.

${ }^{7}$ Sobre essa sociedade, ver Frank Nilton Marcon, Visibilidade e resistência negra em Lages (18881918), São Leopoldo/RG, Dissertação de Mestrado, CGH/Universidade do Rio dos Sinos, 1999, particularmente o subcapítulo "O 'Centro Cívico Cruz e Souza': etnicidade e civilidade". No dia 22 de setembro de 1918, foi fundado em Lages/SC o Centro Cívico Cruz e Souza, uma entidade recreativa, cívica e literária dos "homens de cor". O nome é uma homenagem ao poeta simbolista catarinense João da Cruz e Souza. Segundo seu órgão de imprensa, o jornal Cruะ e Souะa, o núcleo idealizador do Centro Cívico foi um grupo de negros da Escola Noturna dos Amadores da Arte. Dos seus eventos anuais, os mais importantes eram o 13 de Maio, pela comemoração da Abolição da Escravatura, e o 22 de Setembro, pela fundação do Centro Cívico. Cf. F. N. Marcon, Visibilidade e resistência ..., op. cit., p. 130-132.

${ }^{8}$ Henrique Cunha Jr., Textos para o movimento negro, São Paulo, Edicon, 1992.
} 
123 associações negras em São Paulo, entre 1907 e 1937. ' Já Muller encontrou registros da criação de 72 em Porto Alegre, de 1889 a $1920,{ }^{10}$ e Loner, 53 em Pelotas/RS, entre 1888 e $1929.1{ }^{11}$ Havia associações formadas estritamente por mulheres negras, como a Sociedade Brinco das Princesas (1925), em São Paulo, e a Sociedade de Socorros Mútuos Princesa do Sul (1908), em Pelotas.

Simultaneamente, apareceu o que se denomina imprensa negra: jornais publicados por negros e elaborados para tratar de suas questões. Para um dos principais dirigentes negros da época, José Correia Leite, "a comunidade negra tinha necessidade de uma imprensa alternativa", que transmitisse "informações que não se obtinha em outra parte". ${ }^{12}$ Em São Paulo, o primeiro desses jornais foi A Pátria, de 1899, tendo como subtítulo Orgão dos Homens de Cor. Outros títulos também foram publicados nessa cidade: O Combate, em 1912; O Menelick, em 1915; O Bandeirante, em 1918; O Alfinete, em 1918; A Liberdade, em 1918; e A Sentinela, em 1920. No município de Campinas, O Baluarte, em 1903, e O Getulino, em 1923. Um dos principais jornais desse período foi o Clarim da Alvorada, lançado em 1924, sob a direção de José Correia Leite e Jayme Aguiar. ${ }^{13}$ Até 1930, contabiliza-se a existência de, pelo menos, 31 desses jornais circulando em São Paulo. ${ }^{14}$ A imprensa negra conseguia reunir um grupo

\footnotetext{
${ }^{9}$ R. P. Pinto, O movimento negro..., op. cit., p. 84.

${ }^{10}$ Liane S. Muller, As contas do meu rosário são balas de artilharia: irmandade, jornal e associações negras em Porto Alegre (1889-1920), Porto Alegre, Dissertação de Mestrado, IFCH/ PUCRS, 1999.

${ }^{11}$ Beatriz Ana Loner, "Negros: organização e luta em Pelotas", História em Revista, n. 5, Pelotas/RS, 1999, p. 7-28.

${ }^{12}$ José Correia Leite, $E$ disse o velho militante: depoimentos e artigos. Organiæado por Cuti, São Paulo, Secretaria Municipal da Cultura, 1992, p. 33.

${ }^{13}$ Já existe um número razoável de pesquisas referentes à imprensa negra. Ver Roger Bastide, “A imprensa negra do Estado de São Paulo", Boletim de Sociologia, n. 2, São Paulo, Faculdade de Filosofia, Letras e Ciências Humanas/USP, 1951, p. 50-78; Miriam Nicolau Ferrara, A imprensa negra paulista (1915-1963), São Paulo, FFLCH/USP, 1986; Marinalda Garcia, Os arcanos da cidadania: a imprensa negra paulistana nos primórdios do século XX, São Paulo, Dissertação de Mestrado, FFLCH-USP, 1997; Marina Pereira de Almeida Mello, O ressurgir das cinzas: negros paulistas no pós-abolição: identidade e alteridade na imprensa negra paulistana (1915-1923), São Paulo, Dissertação de Mestrado, FFLCH-USP, 1999; Maria Aparecida de Oliveira Lopes, Beleza e ascensão social na imprensa negra paulistana (1920-1940), São Paulo, Dissertação de Mestrado, PUC, 2001; Petrônio Domingues, "A nova abolição. A imprensa negra paulista", Estudos Afro-Asiáticos, ano 27, n. 3, Rio de Janeiro, 2004, p. 89-122. Sobre a imprensa negra em Campinas, ver Cleber da Silva Maciel, Discriminações raciais: negros em Campinas (1888-1926), 2.ed., Campinas, CMU -UNICAMP, 1997, p. 96-102. Sobre a imprensa negra em Pelotas/RS, ver José Antônio dos Santos, Raiou a alvorada: intelectuais negros e imprensa - Pelotas (19071957), Pelotas, Ed. Universitária, 2003, p. 79-152.

${ }^{14}$ Petrônio Domingues, Uma história não contada. Negro, racismo e branqueamento em São Paulo no pós-abolição, São Paulo, SENAC, 2004.
} 
representativo de pessoas para empreender a batalha contra o "preconceito de cor", como se dizia na época. Surgiram jornais dessa mesma natureza em outros estados, como a Raça (1935), em Uberlândia/MG, o União (1918), em Curitiba/PR, O Exemplo (1892), em Porto Alegre/RS, e o Alvorada, em Pelotas/ RS. Este último - publicado com pequenas interrupções de 1907 a 1965 - foi o periódico da imprensa negra de maior longevidade no país. ${ }^{15}$

Esses jornais enfocavam as mais diversas mazelas que afetavam a população negra no âmbito do trabalho, da habitação, da educação e da saúde, tornando-se uma tribuna privilegiada para se pensar em soluções concretas para o problema do racismo na sociedade brasileira. Além disso, as páginas desses periódicos constituíram veículos de denúncia do regime de "segregação racial" que incidia em várias cidades do país, impedindo o negro de ingressar ou freqüentar determinados hotéis, clubes, cinemas, teatros, restaurantes, orfanatos, estabelecimentos comerciais e religiosos, além de algumas escolas, ruas e praças públicas. Nesta etapa, o movimento negro organizado era desprovido de caráter explicitamente político, com um programa definido e projeto ideológico mais amplo. ${ }^{16}$

Na década de 1930, o movimento negro deu um salto qualitativo, com a fundação, em 1931, em São Paulo, da Frente Negra Brasileira (FNB), considerada a sucessora do Centro Cívico Palmares, de $1926 .{ }^{17}$ Estas foram as

\footnotetext{
${ }^{15}$ J. A. dos Santos, Raiou a alvorada..., op. cit., p. 21.

${ }^{16}$ Sobre a emergência da luta política anti-racista, ver Florestan Fernandes, "Os movimentos sociais no meio negro", A integração do negro na sociedade de classes, 2. vol., 3.ed., São Paulo, Ática, 1978, p. 7-115; Paulino de Jesus Francisco Cardoso, A luta contra a apatia: estudo sobre a instituição do movimento negro anti-racista na cidade de São Paulo (1915-1931), São Paulo, Dissertação de Mestrado, PUC, 1993; Clóvis Moura, “Organizações negras”, São Paulo: o povo em movimento; Paul Singer e Vinicius Caldeira Brant (orgs.), Petrópolis/RJ, Vozes/Cebrap, 1980, p. 143-175. Sobre as agremiações negras em Campinas durante a Primeira República, ver C. S. Maciel, Discriminações raciais..., op. cit., p. 73-84.

${ }^{17}$ José Correia Leite e Renato Jardim Moreira, Movimentos sociais no meio negro, São Paulo, mimeog, s/d. Uma bibliografia não desprezível já se ocupou da Frente Negra Brasileira. Ver F. Fernandes, A integração do negro..., op. cit., p. 1-115; José Carlos Gomes da Silva, Os sub urbanos e a outra face da cidade. Negros em São Paulo: cotidiano, lazer e cidadania (1900-1930), Campinas, Dissertação de Mestrado, Unicamp, 1990, p. 162-180; R. P. Pinto, O movimento negro..., op. cit., p. 87-124; Marcelino Félix, As práticas político-pedagógicas da Frente Negra Brasileira na cidade de São Paulo (1931-1937), São Paulo, Dissertação de Mestrado, PUC, 2001; Laiana Lannes de Oliveira, A Frente Negra Brasileira: política e questão racial nos anos 1930, Rio de Janeiro, Dissertação de Mestrado, UERJ, 2002; Maria Aparecida Pinto Silva, A voz da raça: uma expressão negra no Brasil que queria ser branco, São Paulo, Tese de Doutorado, PUC, 2003; Petrônio Domingues, A insurgência de ébano. A história da Frente Negra Brasileira (1931-1937), São Paulo, Tese de Doutorado, FFLCH-USP, 2005.
} 
primeiras organizações negras com reivindicações políticas mais deliberadas. ${ }^{18}$ Na primeira metade do século XX, a FNB foi a mais importante entidade negra do país. Com "delegações” - espécie de filiais - e grupos homônimos em diversos estados (Rio de Janeiro, Minas Gerais, Espírito Santo, Pernambuco, Rio Grande do Sul e Bahia), ${ }^{19}$ arregimentou milhares de "pessoas de cor", conseguindo converter o Movimento Negro Brasileiro em movimento de massa. Pelas estimativas de um de seus dirigentes, a FNB chegou a superar os 20 mil associados. ${ }^{20}$ A entidade desenvolveu um considerável nível de organização, mantendo escola, grupo musical e teatral, time de futebol, departamento jurídico, além de oferecer serviço médico e odontológico, cursos de formação política, de artes e ofícios, assim como publicar um jornal, o A Voz da Raça.

Naquela época, as mulheres negras não tinham apenas importância simbólica no movimento negro. Segundo depoimento do antigo ativista Francisco Lucrécio, elas "eram mais assíduas na luta em favor do negro, de forma que na Frente [Negra] a maior parte eram mulheres. Era um contingente muito grande, eram elas que faziam todo movimento". ${ }^{21}$ Independentemente do exagero de Lucrécio, cumpre assinalar que as mulheres assumiam diversas funções na FNB. A Cruzada Feminina, por exemplo, mobilizava as negras para realizar trabalhos assistencialistas. Já uma outra comissão feminina, as Rosas Negras, organizava bailes e festivais artísticos.

Em 1936, a FNB transformou-se em partido político e pretendia participar das próximas eleições, a fim de capitalizar o voto da "população de cor". Influenciada pela conjuntura internacional de ascensão do nazifascismo,

\footnotetext{
${ }^{18}$ É necessário relativizar essa posição; Beatriz Ana Loner identificou a existência de duas entidades negras de natureza política em Pelotas/RG no início do século XX. A primeira chamava-se Centro Etiópico Monteiro Lopes. Foi fundada em 1909 e promoveu reuniões com mais de 300 pessoas. A segunda entidade política denominava-se Centro Cívico Alcides Bahia e sua criação remonta a 1924. A autora informa que esse mesmo tipo de mobilização também ocorreu em Rio Grande e Bagé no período. Cf. B. A. Loner, Negros: organização e luta..., op. cit., p. 7-28.

${ }^{19}$ Para informações acerca da Frente Negra Pernambucana, ver Maria Auxiliadora Gonçalves da Silva, Encontros e desencontros de um movimento negro, Brasília, Fundação Cultural Palmares, 1994, p. 58-59; para a Frente Negra Baiana, ver Jeferson Bacelar, "A Frente Negra Brasileira na Bahia”, Afro-Ásia, n. 17, Salvador, 1996, p. 73-85; para a Frente Negra Pelotense, ver Beatriz Ana Loner, Classe operária: mobiliæação e organiæação em Pelotas (1888-1937), Rio Grande do Sul, Tese de Doutorado, UFRGS, 1999, p. 399-402, e J. A. dos Santos, Raiou a alvorada..., op. cit., p. 155-185.

${ }^{20}$ Francisco Lucrécio apud Márcio Barbosa (entrevistas e textos), Frente Negra Brasileira: depoimentos, São Paulo, Quilombhoje, 1998, p. 39. R. P. Pinto, O movimento negro em São Paulo..., op. cit., p. 91.

${ }^{21}$ Francisco Lucrécio apud M. Barbosa, Frente Negra Brasileira..., op. cit., p. 37-38.
} 
notabilizou-se por defender um programa político e ideológico autoritário e ultranacionalista. ${ }^{22}$ Sua principal liderança, Arlindo Veiga dos Santos, elogiava publicamente o governo de Benedito Mussolini, na Itália, e Adolfo Hitler, na Alemanha. O subtítulo do jornal $A$ Voz da Raça também era sintomático: "Deus, Pátria, Raça e Família", diferenciando-se do principal lema integralista (movimento de extrema direita brasileiro) apenas no termo "Raça". A FNB mantinha, inclusive, uma milícia, estruturada nos moldes dos boinas verdes do fascismo italiano. A entidade chegou a ser recebida em audiência pelo Presidente da República da época, Getúlio Vargas, tendo algumas de suas reivindicações atendidas, como o fim da proibição de ingresso de negros na guarda civil em São Paulo. ${ }^{23}$ Este episódio indica o poder de barganha que o movimento negro organizado dispunha no cenário político institucionalizado brasileiro. Com a instauração da ditadura do "Estado Novo", em 1937, a Frente Negra Brasileira, assim como todas as demais organizações políticas, foi extinta. O movimento negro, no bojo dos demais movimentos sociais, foi então esvaziado. Nessa fase, a luta pela afirmação racial passava pelo culto à Mãe-Preta e uma das principais palavras de ordem era a defesa da Segunda Abolição. ${ }^{24}$

Vale salientar que, além da Frente Negra Brasileira, outras entidades floresceram com o propósito de promover a integração do negro à sociedade mais abrangente, dentre as quais destacam-se o Clube Negro de Cultura Social $(1932)^{25}$ e a Frente Negra Socialista (1932), em São Paulo; a Sociedade Flor do Abacate, no Rio de Janeiro, a Legião Negra (1934), em Uberlândia/MG, e a Sociedade Henrique Dias (1937), em Salvador.

\section{Segunda fase do Movimento Negro organizado na República (1945-1964): da Segunda República à ditadura militar}

Os anos de vigência do Estado Novo (1937-1945) foram caracterizados por violenta repressão política, inviabilizando qualquer movimento contestatório.

\footnotetext{
${ }^{22}$ P. Domingues, A insurgência de ébano..., op. cit.

${ }^{23}$ Francisco Lucrécio, "Memória histórica: a Frente Negra Brasileira", Revista de Cultura Vozes, 1989, vol. 3, n. 83, p. 332-342.

${ }^{24}$ J. C. Leite, E disse o velho militante..., op. cit. Para uma perscrutação das trajetórias políticas de duas lideranças negras dessa fase, ver Maria Cláudia Cardoso Ferreira, Representações sociais epráticas políticas do movimento negro paulistano: as trajetórias de Correia Leite e Veiga dos Santos (1928-1937), Rio de Janeiro, Dissertação de Mestrado, UERJ, 2005.

${ }^{25}$ Sobre essa organização, ver Petrônio Domingues, "Paladinos da liberdade: a experiência do Clube Negro de Cultura Social em São Paulo (1932-1938)", Revista de História, n. 150, São Paulo, 2004, p. 57-79.
} 
Mas, com a queda da ditadura "Varguista", ressurgiu, na cena política do país, o movimento negro organizado que, por sinal, ampliou seu raio de ação. $\mathrm{Na}$ concepção de Guimarães, o protesto negro aumentou por diversas razões:

Primeiro, porque a discriminação racial, à medida que se ampliavam os mercados e a competição, também se tornava mais problemática; segundo, porque os preconceitos e os estereótipos continuavam a perseguir os negros; terceiro, porque grande parte da população "de cor" continuava marginalizada em favelas, mucambos, alagados e na agricultura de subsistência. ${ }^{26}$

Esta fase do movimento negro, entretanto, não teria o mesmo poder de aglutinação da anterior.

Dessa época, um dos principais agrupamentos foi a União dos Homens de Cor. Também intitulada Uagacê ou simplesmente UHC, foi fundada por João Cabral Alves, em Porto Alegre, em janeiro de 1943. Já no primeiro artigo do estatuto, a entidade declarava que sua finalidade central era "elevar o nível econômico, e intelectual das pessoas de cor em todo o território nacional, para torná-las aptas a ingressarem na vida social e administrativa do país, em todos os setores de suas atividades". A UHC era constituída de uma complexa estrutura organizativa. A diretoria nacional era formada pelos fundadores e dividia-se nos cargos de presidente, secretário-geral, inspetor geral, tesoureiro, chefe dos departamentos (de saúde e educação), consultor jurídico e conselheiros (ou diretores).

Chama a atenção a escalada expansionista da UHC. Na segunda metade da década de 1940, ela abriu sucursal ou possuía representantes em pelo menos 10 Estados da Federação (Minas Gerais, Santa Catarina, Bahia, Maranhão, Ceará, Rio Grande do Sul, São Paulo, Espírito Santo, Piauí e Paraná), estando presente em inúmeros municípios do interior. Somente no estado do Paraná, a UHC mantinha contato com 23 cidades em 1948. Em linhas gerais, sua atuação era marcada pela promoção de debates na imprensa local, publicação de jornais próprios, serviços de assistência jurídica e médica, aulas de alfabetização, ações de voluntariado e participação em campanhas eleitorais.

No início da década de 1950, representantes da UHC foram recebidos em audiência pelo então Presidente Getúlio Vargas, ocasião em que lhe foi apresentada uma série de reivindicações a favor da "população de cor”. No Rio de Janeiro, os dirigentes da entidade tornaram-se "figuras proeminentes, seja no ativismo seja na vida pública. Este é o caso, por exemplo, de José Bernardo

${ }^{26}$ Antônio S. A. Guimarães, Classes, rạ̧as e democracia, São Paulo, Editora 34, 2002, p. 88. 
da Silva, eleito deputado federal por dois mandatos consecutivos a partir de 1954". ${ }^{27}$ Algumas dissidências ou mesmo agremiações homônimas surgiram a partir da UHC. Dentre elas, merecem nota o aparecimento da União Cultural dos Homens de Cor (UCHC), que era dirigida por José Pompílio da Hora, no Rio de Janeiro, e a fundação da União Catarinense dos Homens de Cor (UCHC), em Blumenau, em 1962. A implantação da ditadura militar, em 1964, concorreu para o arrefecimento de muitos grupos dos movimentos sociais no país, e a UHC não ficou incólume a esse processo.

Outro agrupamento importante foi o Teatro Experimental do Negro (TEN), fundado no Rio de Janeiro, em 1944, e que tinha Abdias do Nascimento como sua principal liderança. ${ }^{28}$ A proposta original era formar um grupo teatral constituído apenas por atores negros, mas progressivamente o TEN adquiriu um caráter mais amplo: publicou o jornal Quilombo, passou a oferecer curso de alfabetização, de corte e costura; fundou o Instituto Nacional do Negro, o Museu do Negro; organizou o I Congresso do Negro Brasileiro; promoveu a eleição da Rainha da Mulata e da Boneca de Pixe; tempo depois, realizou o concurso de artes plásticas que teve como tema Cristo Negro, com repercussão na opinião pública. ${ }^{29}$ Defendendo os direitos civis dos negros na qualidade de direitos humanos, o TEN propugnava a criação de uma legislação antidiscriminatória para o país.

O grupo foi um dos pioneiros a trazer para o país as propostas do movimento da negritude francesa, que, naquele instante, mobilizava a atenção

${ }^{27}$ Joselina da Silva, União dos homens de cor (UHC): uma rede do movimento social negro, após o Estado Novo, Rio de Janeiro, Tese de Doutorado, UERJ, 2005, p. 216. Da mesma autora, ver "A União dos Homens de Cor: aspectos do movimento negro dos anos 40 e 50", Estudos Afro-Asiáticos, ano 25, n. 2, Rio de Janeiro, 2003, p. 215-236.

${ }^{28}$ Vários trabalhos já se debruçaram em torno da experiência histórica do Teatro Experimental do Negro. Ver Luís de Aguiar Costa Pinto, O Negro no Rio de Janeiro. Relações de raça numa sociedade em mudança, São Paulo, Ed. Nacional, 1953, p. 246-261; Ricardo Gaspar Muller, Identidade e cidadania: o Teatro Experimental do Negro, Belo Horizonte, Dissertação de Mestrado, FFCH/UFMG, 1983. Uma versão sintetizada dessa dissertação foi publicada pelo autor sob a forma de artigo: "Identidade e cidadania: o Teatro Experimental do Negro", Dionysos, n. 28, Rio de Janeiro, 1988, p. 11-52. Ver também Maria Angélica da Motta Maués, "Entre o branqueamento e a negritude: o TEN e o debate da questão racial", Dionysos, n. 28, Rio de Janeiro, 1988, p. 89-101; Elizabeth Larkin Nascimento, O sortilégio da cor. Identidade afro-descendente no Brasil, São Paulo, Tese de Doutorado, IP/USP, 2000; Ieda Maria Martins, A cena em sombras, São Paulo, Ed. Perspectiva, 1995. Sobre o líder do TEN, ver Márcio José de Macedo, Abdias do Nascimento: a trajetória de um negro revoltado (1914-1968), São Paulo, Dissertação de Mestrado, FFLCH/USP, 2005.

${ }^{29}$ Abdias do Nascimento, "Teatro negro no Brasil. Uma experiência sócio-racial”, Revista Civilização Brasileira, Caderno Especial, n. 2, Rio de Janeiro, 1968, p. 193-211. 
do movimento negro internacional e que, posteriormente, serviu de base ideológica para a luta de libertação nacional dos países africanos. Com a instauração da ditadura militar em 1964, o TEN ficou moribundo, sendo praticamente extinto em 1968, quando seu principal dirigente, Abdias do Nascimento, partiu para o auto-exílio nos Estados Unidos. Na avaliação de Gonzalez, o TEN "significou um grande avanço no processo de organização da comunidade [negra]". ${ }^{30}$

Nessa segunda etapa do movimento negro, a UHC ou o TEN não eram os únicos grupos que empreendiam a luta anti-racista, mas foram aqueles cujas ações adquiriram mais visibilidade. Além deles, articulou-se o Conselho Nacional das Mulheres Negras, em 1950. Em Minas Gerais, foi criado o Grêmio Literário Cruz e Souza, em 1943; e a Associação José do Patrocínio, em 1951. Em São Paulo, surgiram a Associação do Negro Brasileiro, em 1945, a Frente Negra Trabalhista e a Associação Cultural do Negro, em 1954, com inserção no meio negro mais tradicional. No Rio de Janeiro, em 1944, ainda veio a lume o Comitê Democrático Afro-Brasileiro - que defendeu a convocação da Assembléia Constituinte, a Anistia e o fim do preconceito racial -, entre dezenas de outros grupos dispersos pelo Brasil. ${ }^{31}$

Outrossim, é importante assinalar que, nessa segunda etapa, a imprensa negra ganhou novo impulso, com a publicação de diversos jornais de protesto pelo país. Em São Paulo, surgiram o Alvorada (1945), O Novo Horizonte (1946), Notícias de Ébano (1957), O Mutirão (1958), Níger (1960); em Curitiba, o União (1947); no Rio de Janeiro, o Redenção (1950) e A Voz da Negritude (1952). Registrou-se, ainda, o aparecimento da revista Senzala (1946), em São Paulo. Apesar do crescente acúmulo de experiência, o movimento negro ficou isolado politicamente naquele momento, não podendo contar efetivamente com o apoio das forças políticas, seja da direita, seja da esquerda marxista. Um episódio ilustra esse estado de isolamento. Em 1946, o senador Hamilton Nogueira (UDN) apresentou à Assembléia Nacional Constituinte um projeto

${ }^{30}$ Lélia Gonzalez, "O movimento negro na última década”, Lugar de negro, Lélia Gonzalez e Carlos Hasenbalg (orgs.), Rio de Janeiro, Editora Marcozero, 1982, p. 24.

${ }^{31}$ Sobre a segunda fase do movimento negro, também ver Michael George Hanchard, Orfeu e o poder. Movimento negro no Rio de Janeiro e São Paulo (1945-1988), Trad. Vera Ribeiro, Rio de Janeiro, Ed. UERJ, 2001; José Jorge Siqueira, Entre orfeu e xangô: a emergência de uma nova consciência sobre a questão do negro no Brasil (1944-1968), Rio de Janeiro, Tese de Doutorado, UFRJ, 1997, e Maria Aparecida Pinto Silva, Visibilidade e respeitabilidade: a luta dos negros nas associações culturais e recreativas de São Paulo (1930-1960), São Paulo, Dissertação de Mestrado, PUC, 1997. 
de lei antidiscriminatória, formulado originalmente na Convenção Nacional do Negro, um ano antes, em 1945. Colocado em votação, o Partido Comunista Brasileiro (PCB) se opôs ao projeto, alegando que a lei iria "restringir o conceito amplo de democracia". ${ }^{32}$ Para o PCB, as reivindicações específicas dos negros eram um equívoco, pois dividiam a luta dos trabalhadores e, por conseguinte, represavam a marcha da revolução socialista no país. Como resultado, o movimento negro ficou praticamente abandonado por décadas, inclusive pelos setores políticos mais progressistas. A primeira lei antidiscriminatória do país, batizada de Afonso Arinos, só foi aprovada no Congresso Nacional em 1951, após o escândalo de racismo que envolveu a bailarina negra norte-americana Katherine Dunham, impedida de se hospedar num hotel em São Paulo. ${ }^{33}$

\section{Terceira fase do Movimento Negro organizado na República (1978-2000): do início do processo de redemocratização à República Nova}

O golpe militar de 1964 representou uma derrota, ainda que temporária, para a luta política dos negros. Ele desarticulou uma coalizão de forças que palmilhava no enfrentamento do "preconceito de cor" no país. Como conseqüência, o Movimento Negro organizado entrou em refluxo. Seus militantes eram estigmatizados e acusados pelos militares de criar um problema que supostamente não existia, o racismo no Brasil. ${ }^{34}$ De acordo com Gonzalez, a repressão "desmobilizou as lideranças negras, lançando-as numa espécie de semiclandestinidade". ${ }^{35}$ A discussão pública da questão racial foi praticamente banida. Cunha Jr. aponta as dificuldades que havia para superar o desmantelamento do movimento negro naquela época:

tínhamos três tipos de problemas, o isolamento político, ditadura militar e o esvaziamento dos movimentos passados. Posso dizer que em 1970 era difícil reunir mais que meia dúzia de militantes do movimento negro. ${ }^{36}$

\footnotetext{
32 Abdias do Nascimento, "Depoimento", Memórias do exílio, Pedro Celso Uchoa e Ramos Jovelino (orgs.), São Paulo, Livramento, 1978, p. 33.

${ }_{33}$ Abdias do Nascimento, O negro revoltado, 2.ed., Rio de Janeiro, Nova Fronteira, 1982, p. 39.

34 Thomas Skidmore julga de maneira correta quando afirma que, no período da ditadura militar, "a elite brasileira defendia tenazmente a imagem do Brasil como uma democracia racial. Assim agia, de inúmeras maneiras. Uma dessas maneiras era rotular de "não brasileiros" quem quer que levantasse sérias questões sobre relações raciais no Brasil". Thomas Skidmore, O Brasil visto de fora, Rio de Janeiro, Paz e Terra, 1994, p. 137.

${ }^{35}$ L. Gonzalez, O movimento negro na última..., op. cit., p. 30.

${ }^{36}$ H. Cunha Jr., Textos para o movimento..., op. cit., p. 65.
} 
A reorganização política da pugna anti-racista apenas aconteceu no final da década de 1970, no bojo do ascenso dos movimentos populares, sindical e estudantil. Isto não significa que - no interregno de recrudescimento da ditadura - os negros não tenham realizado algumas ações. Em São Paulo, por exemplo, em 1972, um grupo de estudantes e artistas formou o Centro de Cultura e Arte Negra (CECAN); a imprensa negra, por sua vez, timidamente deu sinais de vida, com os jornais Árvore das Palavras (1974), O Quadro (1974), em São Paulo; Biluga (1974), em São Caetano/SP, e Nagô (1975), em São Carlos/SP. Em Porto Alegre, nasceu o Grupo Palmares (1971), o primeiro no país a defender a substituição das comemorações do 13 de Maio para o 20 de Novembro. No Rio de Janeiro, explodiu, no interior da juventude negra, o movimento Soul, depois batizado de Black Rio. Nesse mesmo estado, foi fundado o Instituto de Pesquisa das Culturas Negras (IPGN), em 1976. ${ }^{37}$ Entretanto, tais iniciativas, além de fragmentadas, não tinham um sentido político de enfrentamento com o regime. Só em 1978, com a fundação do Movimento Negro Unificado (MNU), tem-se a volta à cena política do país do movimento negro organizado. ${ }^{38} \mathrm{Mas}$, afinal, como ocorreu esse processo?

No plano externo, o protesto negro contemporâneo se inspirou, de um lado, na luta a favor dos direitos civis dos negros estadunidenses, onde se projetaram lideranças como Martin Luther King, Malcon X e organizações negras marxistas, como os Panteras Negras, e, de outro, nos movimentos de libertação dos países africanos, sobretudo de língua portuguesa, como Guiné Bissau, Moçambique e Angola. Tais influências externas contribuíram para o Movimento Negro Unificado ter assumido um discurso radicalizado contra a discriminação racial.

No plano interno, o embrião do Movimento Negro Unificado foi a organização marxista, de orientação trotskista, Convergência Socialista. Ela foi a escola de formação política e ideológica de várias lideranças importantes dessa nova fase do movimento negro. Havia, na Convergência Socialista, um grupo de militantes negros que entendia que a luta anti-racista tinha que ser combinada com a luta revolucionária anticapitalista. Na concepção desses militantes, o capitalismo era o sistema que alimentava e se beneficiava do racismo; assim, só com a derrubada desse sistema e a conseqüente construção

${ }^{37}$ Helene Monteiro, O ressurgimento do movimento negro no Rio de Janeiro na década de 1970, Rio de Janeiro, Dissertação de Mestrado, IFCS/UFRJ, 1991.

${ }^{38}$ Maria E. do Nascimento, A estratégia da desigualdade; o movimento negro dos anos 70, São Paulo, Dissertação de Mestrado, PUC, 1989. 
de uma sociedade igualitária era possível superar o racismo. A política que conjugava raça e classe atraiu aqueles ativistas que cumpriram um papel decisivo na fundação do Movimento Negro Unificado: Flávio Carrança, Hamilton Cardoso, Vanderlei José Maria, Milton Barbosa, Rafael Pinto, Jamu Minka e Neuza Pereira. Entre 1977 e 1979, a Convergência Socialista publicou um jornal chamado Versus, que destinava uma coluna, a "Afro-Latino América", para o núcleo socialista negro escrever seus artigos conclamando à "guerra" revolucionária de combate ao racismo e ao capitalismo. Segundo Hanchard, as posturas táticas e ideológicas assumidas pela seção "Afro-Latino América" foram decisivas para o MNU e para o movimento em geral:

Pela primeira vez no Brasil a defesa de uma posição quanto à raça e à classe não foi marginalizada pela intelectualidade afro-brasileira e, na verdade, passou a suplantar os modelos conformista e assimilacionista como postura dominante do movimento negro. ${ }^{39}$

Assim, no contexto de rearticulação do movimento negro, aconteceu uma reunião em São Paulo, no dia 18 de junho de 1978, com diversos grupos e entidades negras (CECAN, Grupo Afro-Latino América, Câmara do Comércio Afro-Brasileiro, Jornal Abertura, Jornal Capoeira e Grupo de Atletas e Grupo de Artistas Negros). Nesta reunião, decidiu-se criar o Movimento Unificado Contra a Discriminação Racial (MUCDR), e a primeira atividade da nova organização foi um ato público em repúdio à discriminação racial sofrida por quatro jovens no Clube de Regatas Tietê e em protesto à morte de Robson Silveira da Luz, trabalhador e pai de família negro, torturado até a morte no $44^{\circ}$ Distrito de Guainases. O ato público foi realizado no dia 7 de julho de 1978, nas escadarias do Teatro Municipal em São Paulo, reunindo cerca de 2 mil pessoas, e "considerado pelo MUCDR como o maior avanço político realizado pelo negro na luta contra o racismo". ${ }^{40} \mathrm{O}$ evento recebeu moções de apoio de alguns estados, inclusive de várias associações negras cariocas: Escola

\footnotetext{
${ }^{39}$ M. G. Hanchard, Orfeu e o poder..., op. cit., p. 148. Não só os negros da Convergência Socialista concebiam o protesto anti-racista como indissociável da luta classista de enfrentamento do capitalismo. Em realidade, essa visão se arvorou como a predominante no movimento negro organizado do período. As palavras de uma de suas principais lideranças, Lélia Gonzalez, são sintomáticas: "Hoje não dá mais pra sustentar posições culturalistas, intelectualistas, coisas que tais, e divorciadas da realidade vivida pelas massas negras. Sendo contra ou a favor, não dá mais pra ignorar essa questão concreta, colocada pelo MNU: a articulação entre raça e classe". Cf. L. Gonzalez, O movimento negro na última ..., op. cit., p. 64.

${ }^{40}$ Movimento Negro Unificado, 1978-1988: 10 anos de luta contra o racismo, São Paulo, Confraria do Livro, 1988, p. 78.
} 
de Samba Quilombo, Renascença Clube, Núcleo Negro Socialista, Centro de Estudos Brasil-África (CEBA) e o IPCN.

Uma Carta Aberta, distribuída à população, concitava os negros a formarem "Centros de Luta" nos bairros, nas vilas, nas prisões, nos terreiros de candomblé e umbanda, nos locais de trabalho e nas escolas, a fim de organizar a peleja contra a opressão racial, a violência policial, o desemprego, o subemprego e a marginalização da população negra. Na $1^{a}$ Assembléia Nacional de Organização e Estruturação da entidade, no dia 23 de julho, foi adicionada a palavra Negro ao nome do movimento, passando, assim, a ser chamado Movimento Negro Unificado Contra a Discriminação Racial (MNUCDR). Neste mesmo ano, foram aprovados o Estatuto, a Carta de Princípios e o Programa de Ação. No seu $1^{\circ}$ Congresso, o MNUCDR conseguiu reunir delegados de vários estados. Como a luta prioritária do movimento era contra a discriminação racial, seu nome foi simplificado para Movimento Negro Unificado (MNU).

No Programa de Ação, de 1982, o MNU defendia as seguintes reivindicações "mínimas": desmistificação da democracia racial brasileira; organização política da população negra; transformação do Movimento Negro em movimento de massas; formação de um amplo leque de alianças na luta contra o racismo e a exploração do trabalhador; organização para enfrentar a violência policial; organização nos sindicatos e partidos políticos; luta pela introdução da História da África e do Negro no Brasil nos currículos escolares, bem como a busca pelo apoio internacional contra o racismo no país.

Concomitante à reorganização das entidades negras, registrou-se a volta da imprensa negra. Alguns dos principais jornais desse período foram: SINBA (1977), Africus (1982), Nizinga (1984), no Rio de Janeiro; Jornegro (1978), ${ }^{41}$ O Saci (1978), Abertura (1978), Vissungo (1979), em São Paulo; Pixaim (1979), em São José dos Campos/SP; Quilombo (1980), em Piracicaba/SP; Nêgo (1981), em Salvador/BA; Tição (1977), no Rio Grande do Sul, além da revista Ébano (1980), em São Paulo.

O nascimento do MNU significou um marco na história do protesto negro do país, porque, entre outros motivos, desenvolveu-se a proposta de unificar a luta de todos os grupos e organizações anti-racistas em escala nacional. ${ }^{42} \mathrm{O}$ objetivo era fortalecer o poder político do movimento negro. Nesta nova fase,

${ }^{41}$ Sobre este jornal, ver Ubirajara Damaceno da Motta, Jornegro: um projeto de comunicação afro-brasileira, São Bernardo do Campo-SP, Dissertação de Mestrado, Instituto Medodista de Ensino Superior, 1986.

${ }^{42} \mathrm{~L}$. Gonzalez, O movimento negro na última..., op. cit. 
a estratégia que prevaleceu no movimento foi a de combinar a luta do negro com a de todos os oprimidos da sociedade. ${ }^{43}$ A tônica era contestar a ordem social vigente e, simultaneamente, desferir a denúncia pública do problema do racismo. Pela primeira vez na história, o movimento negro apregoava como uma de suas palavras de ordem a consigna: "negro no poder!".

O culto da Mãe Preta, visto como símbolo da passividade do negro, passou a ser execrado. O 13 de Maio, dia de comemoração festiva da abolição da escravatura, transformou-se em Dia Nacional de Denúncia Contra o Racismo. A data de celebração do MNU passou a ser o 20 de Novembro (presumível dia da morte de Zumbi dos Palmares), a qual foi eleita como Dia Nacional de Consciência Negra. ${ }^{44}$ Zumbi, aliás, foi escolhido como símbolo da resistência à opressão racial. Para os ativistas, "Zumbi vive ainda, pois a luta não acabou". O movimento negro organizado, com suas reivindicações específicas, adquiriu certa visibilidade pública. Como escreve Cunha Jr., naquela época "a grande imprensa descobriu existir um movimento negro no Brasil". ${ }^{45}$

Para incentivar o negro a assumir sua condição racial, o MNU resolveu não só despojar o termo "negro" de sua conotação pejorativa, mas o adotou oficialmente para designar todos os descendentes de africanos escravizados no país. Assim, ele deixou de ser considerado ofensivo e passou a ser usado com orgulho pelos ativistas, o que não acontecia tempos atrás. O termo "homem de cor", por sua vez, foi praticamente proscrito.

Naquele período, o movimento negro passou a intervir amiúde no terreno educacional, ${ }^{46}$ com proposições fundadas na revisão dos conteúdos preconceituosos dos livros didáticos; na capacitação de professores para desenvolver uma pedagogia interétnica; na reavaliação do papel do negro na história do Brasil e, por fim, erigiu-se a bandeira da inclusão do ensino da história da

\footnotetext{
${ }^{43}$ Sobre essa questão, ver Florestan Fernandes, Significado do protesto negro, São Paulo, Cortez/ Autores Associados, 1989, especialmente os capítulos "O protesto negro" e "Luta de raças e de classes".

${ }^{44}$ Oliveira Silveira, "Vinte de Novembro: história e conteúdo", Educação e ações afirmativas: entre a injustiça simbólica e a injustiça econômica, P. B. G. Silva e V. R. Silvério (orgs.), Brasília, INEP/MEG, 2003, p. 21-42. Também ver Micênio C. Lopes dos Santos, 13 de Maio, 20 de Novembro: uma descrição da construção de símbolos raciais e nacionais, Rio de Janeiro, Dissertação de Mestrado, IFCS/UFRJ, 1991.

${ }^{45}$ H. Cunha Jr., Textos para o movimento..., op. cit., p. 66.

${ }^{46}$ João Baptista Borges Pereira, "Parâmetros ideológicos do projeto político de negros em São Paulo: um ensaio da antropologia política”, Revista do Instituto de Estudos Brasileiros, n. 24, São Paulo, 1982, p. 53-61.
} 
África nos currículos escolares. ${ }^{47}$ Reivindicava-se, igualmente, a emergência de uma literatura "negra" em detrimento à literatura de base eurocêntrica.

O movimento negro organizado "africanizou-se". A partir daquele instante, as lides contra o racismo tinham como uma das premissas a promoção de uma identidade étnica específica do negro. O discurso tanto da negritude quanto do resgate das raízes ancestrais norteou o comportamento da militância. Houve a incorporação do padrão de beleza, da indumentária e da culinária africana. Na avaliação de Maués, esta fase "se caracteriza por um rompimento tanto no que se refere a uma adesão aos valores (brancos) da primeira, como à posição no mínimo vacilante da segunda". ${ }^{4}$

Também se desencadeou um processo de questionamento dos nomes ocidentais como única referência de identidade dos negros brasileiros. Muitas crianças negras, recém-nascidas, passaram a ser registradas com nomes africanos, sobretudo de origem iorubá. Como assinala Maués,

trata-se da adesão a uma estética da negritude - vestuário, penteados, adereços, ditos afro. Além de sua própria imagem, a adesão deve passar pela valorização e mesmo adoção de elementos da "cultura africana", tais como música, dança, jogos e até hábitos alimentares, traduzidos nos jornais em receitas atribuídas aos antigos descendentes de escravos. Para completar o modelo, insiste-se na adoção, para as crianças, de nomes africanos, que aparecem sempre nos jornais acompanhados de sua tradução para o português. ${ }^{49}$

Até no terreno religioso houve um processo revisionista. Se nas etapas anteriores o movimento negro era notadamente cristão, impôs-se a cobrança moral para que a nova geração de ativistas assumisse as religiões de matriz africana, particularmente o candomblé, tomado como principal guardião da fé ancestral.

O movimento negro ainda desenvolveu, nessa terceira fase, uma campanha política contra a mestiçagem, apresentando-a como uma armadilha ideológica alienadora. A avaliação era de que a mestiçagem sempre teria cumprido um papel negativo de diluição da identidade do negro no Brasil. O mestiço seria um entrave para a mobilização política daquele segmento da população. Segundo essa geração de ativistas, a mestiçagem historicamente

\footnotetext{
${ }^{47}$ Manoel de Almeida Cruz, Alternativas para combater o racismo, Salvador, Núcleo Cultural Afro-Brasileiro, 1989.

${ }^{48}$ Maria Angélica Motta Maués, “Da 'branca senhora' ao 'negro herói’: a trajetória de um discurso racial”, Estudos Afro-Asiáticos, n. 21, Rio de Janeiro, 1991, p. 125.

${ }^{49}$ M. A. Motta Maués, Da branca senhora..., op. cit., p. 127.
} 
esteve a serviço do branqueamento, e o mestiço seria o primeiro passo desse processo. Por isso, condenavam o discurso oficial pró-mestiçagem. Como contrapartida, defendiam os casamentos endogâmicos e a constituição da família negra. O homem negro teria que, inexoravelmente, casar-se com a mulher do mesmo grupo racial e vice-versa. Por essa concepção, os casamentos interraciais produziam o fenômeno da mestiçagem que, por sua vez, redundariam, a longo prazo, em etnocídio. O discurso nacional pró-mestiçagem era, assim, concebido como uma estratégia da classe dominante para provocar o "genocídio" do negro no país. ${ }^{50}$

Os dois aspectos distintivos dessa fase na opinião de Cardoso foram: "de um lado, a introdução pelos movimentos negro, no ideário político da sociedade (brasileira), de reivindicações anti-racistas e, de outro, a crescente consolidação de uma nova identidade racial e cultural para o negro" no país. ${ }^{51}$

\section{Quadro comparativo da trajetória do movimento negro na República}

\begin{tabular}{|l|l|l|l|}
\hline $\begin{array}{c}\text { Movimento Negro } \\
\text { Brasileiro }\end{array}$ & \multicolumn{1}{|c|}{$\begin{array}{c}\text { Primeira Fase } \\
(1889-1937)\end{array}$} & \multicolumn{1}{|c|}{$\begin{array}{c}\text { Segunda Fase } \\
(1945-1964)\end{array}$} & $\begin{array}{c}\text { Terceira Fase } \\
(1978-2000)\end{array}$ \\
\hline $\begin{array}{l}\text { Tipo de discurso } \\
\text { racial predominante }\end{array}$ & Moderado & Moderado & Contundente \\
\hline $\begin{array}{l}\text { Estratégia cultural } \\
\text { de "inclusão" }\end{array}$ & Assimilacionista & Integracionista & $\begin{array}{l}\text { Diferencialista } \\
\text { (igualdade na } \\
\text { diferença) }\end{array}$ \\
\hline $\begin{array}{l}\text { Principais princípios } \\
\text { ideológicos e } \\
\text { posições políticas }\end{array}$ & $\begin{array}{l}\text { Nacionalismo e } \\
\text { defesa das forças } \\
\text { políticas de } \\
\text { "direita", nos } \\
\text { anos 1930 }\end{array}$ & $\begin{array}{l}\text { Nacionalismo e } \\
\text { defesa das forças } \\
\text { políticas de "centro" } \\
\text { e de "direita", nos } \\
\text { anos 1940 e 1950 }\end{array}$ & $\begin{array}{l}\text { Internacionalismo } \\
\text { e defesa das forças } \\
\text { políticas da esquerda } \\
\text { marxista, nos anos } \\
1970 \text { e 1980 }\end{array}$ \\
\hline
\end{tabular}

\footnotetext{
${ }^{50}$ Abdias do Nascimento, O genocídio do negro brasileiro, Rio de Janeiro, Paz e Terra, 1978.

${ }^{51}$ Hamilton B. Cardoso, "Limites do confronto racial e aspectos da experiência negra do Brasil”, Movimentos sociais na transição democrática, Emir Sader (org.), São Paulo, Cortez, 1987, p. 101. Desse mesmo autor, ver "História recente: dez anos de movimento negro", Teoria e debate, n. 2, 1988, p. 10-13. No que tange à história do movimento negro contemporâneo em âmbito regional, ver para o caso da Bahia: Jônatas C. da Silva, "Histórias de lutas negras: memórias do surgimento do movimento negro na Bahia", Escravidão e invenção da liberdade; estudos sobre o negro no Brasil, João José Reis (org.), São Paulo, Brasiliense, 1988, p. 275-288; para o caso de Pernambuco: Maria Auxiliadora Gonçalves da Silva, Encontros e desencontros de um movimento negro, Brasília, Fundação Cultural Palmares, 1994; para o caso de Belo Horizonte: Marcos Cardoso, Movimento negro em Belo Horizonte: 1978-1998, Belo Horizonte, Mazza edições, 2002; e, para o caso de Sergipe, Paulo Santos Dantas, Construção de identidade negra e estratégia de poder: o movimento negro sergipano na década de 90, Salvador, Dissertação de Mestrado, UFBA, 2003.
} 


\begin{tabular}{|c|c|c|c|}
\hline $\begin{array}{c}\text { Movimento Negro } \\
\text { Brasileiro }\end{array}$ & $\begin{array}{c}\text { Primeira Fase } \\
(1889-1937)\end{array}$ & $\begin{array}{c}\text { Segunda Fase } \\
(1945-1964)\end{array}$ & $\begin{array}{l}\text { Terceira Fase } \\
(1978-2000)\end{array}$ \\
\hline $\begin{array}{l}\text { Conjuntura } \\
\text { internacional }\end{array}$ & $\begin{array}{l}\text { Movimento } \\
\text { nazifascista e } \\
\text { pan-africanista }\end{array}$ & $\begin{array}{l}\text { Movimento da } \\
\text { negritude e de } \\
\text { descolonização da } \\
\text { África }\end{array}$ & $\begin{array}{l}\text { Afrocentrismo, } \\
\text { movimento dos } \\
\text { direitos civis nos } \\
\text { Estados Unidos e de } \\
\text { descolonização da } \\
\text { África } \\
\end{array}$ \\
\hline $\begin{array}{l}\text { Principais termos de } \\
\text { auto-identificação }\end{array}$ & $\begin{array}{l}\text { Homem de cor, } \\
\text { negro e preto }\end{array}$ & $\begin{array}{l}\text { Homem de cor, } \\
\text { negro e preto }\end{array}$ & $\begin{array}{l}\text { Adoção "oficial" } \\
\text { do termo "negro". } \\
\text { Posteriormente, } \\
\text { usa-se, também, o } \\
\text { "afro-brasileiro" e } \\
\text { "afro-descendente" }\end{array}$ \\
\hline $\begin{array}{l}\text { Causa da } \\
\text { marginalização do } \\
\text { negro }\end{array}$ & $\begin{array}{l}\text { A escravidão e o } \\
\text { despreparo moral/ } \\
\text { educacional }\end{array}$ & $\begin{array}{l}\text { A escravidão e o } \\
\text { despreparo cultural/ } \\
\text { educacional }\end{array}$ & $\begin{array}{l}\text { A escravidão e o } \\
\text { sistema capitalista }\end{array}$ \\
\hline $\begin{array}{l}\text { Solução para o } \\
\text { racismo }\end{array}$ & $\begin{array}{l}\text { Pela via educacional } \\
\text { e moral, nos marcos } \\
\text { do capitalismo ou da } \\
\text { sociedade burguesa }\end{array}$ & $\begin{array}{l}\text { Pela via educacional } \\
\text { e cultural, } \\
\text { eliminando o } \\
\text { complexo de } \\
\text { inferioridade do } \\
\text { negro e reeducando } \\
\text { racialmente o } \\
\text { branco, nos marcos } \\
\text { do capitalismo ou } \\
\text { sociedade burguesa } \\
\end{array}$ & $\begin{array}{l}\text { Pela via política } \\
\text { ("negro no poder!"), } \\
\text { nos marcos de uma } \\
\text { sociedade socialista, } \\
\text { a única que seria } \\
\text { capaz de eliminar } \\
\text { com todas as } \\
\text { formas de opressão, } \\
\text { inclusive a racial }\end{array}$ \\
\hline Métodos de lutas & $\begin{array}{l}\text { Criação de } \\
\text { agremiações negras, } \\
\text { palestras, atos } \\
\text { públicos "cívicos" e } \\
\text { publicação de jornais }\end{array}$ & $\begin{array}{l}\text { Teatro, imprensa, } \\
\text { eventos } \\
\text { "acadêmicos" e } \\
\text { ações visando à } \\
\text { sensibilização da } \\
\text { elite branca para o } \\
\text { problema do negro } \\
\text { no país }\end{array}$ & $\begin{array}{l}\text { Manifestações } \\
\text { públicas, imprensa, } \\
\text { formação de comitês } \\
\text { de base, formação } \\
\text { de um movimento } \\
\text { nacional }\end{array}$ \\
\hline $\begin{array}{l}\text { Relação com } \\
\text { o "mito" da } \\
\text { democracia racial }\end{array}$ & $\begin{array}{l}\text { Denúncia } \\
\text { assistemática } \\
\text { do "mito" da } \\
\text { democracia racial }\end{array}$ & $\begin{array}{l}\text { Denúncia } \\
\text { assistemática } \\
\text { do "mito" da } \\
\text { democracia racial }\end{array}$ & $\begin{array}{l}\text { Denúncia } \\
\text { sistemática } \\
\text { do "mito" da } \\
\text { democracia racial }\end{array}$ \\
\hline $\begin{array}{l}\text { Capacidade de } \\
\text { mobilização }\end{array}$ & $\begin{array}{l}\text { Movimento social } \\
\text { que chegou a ter um } \\
\text { caráter de massa }\end{array}$ & $\begin{array}{l}\text { Movimento social de } \\
\text { vanguarda }\end{array}$ & $\begin{array}{l}\text { Movimento social de } \\
\text { vanguarda }\end{array}$ \\
\hline $\begin{array}{l}\text { Relação com a } \\
\text { "cultura negra" }\end{array}$ & $\begin{array}{l}\text { Distanciamento } \\
\text { frente alguns } \\
\text { símbolos associados } \\
\text { à cultura negra } \\
\text { (capoeira, samba, } \\
\text { religiões de matriz } \\
\text { africana) }\end{array}$ & $\begin{array}{l}\text { Ambigüidade } \\
\text { valorativa diante } \\
\text { de alguns símbolos } \\
\text { associados à cultura } \\
\text { negra (capoeira, } \\
\text { samba, religiões de } \\
\text { matriz africana) } \\
\end{array}$ & $\begin{array}{l}\text { Valorização dos } \\
\text { símbolos associados } \\
\text { à cultura negra } \\
\text { (capoeira, samba, } \\
\text { religiões de matriz } \\
\text { africana, sobretudo o } \\
\text { candomblé) }\end{array}$ \\
\hline
\end{tabular}




\begin{tabular}{|l|l|l|l|}
\hline $\begin{array}{c}\text { Movimento Negro } \\
\text { Brasileiro }\end{array}$ & \multicolumn{1}{|c|}{$\begin{array}{c}\text { Primeira Fase } \\
(1889-1937)\end{array}$} & \multicolumn{1}{|c|}{$\begin{array}{c}\text { Segunda Fase } \\
(1945-1964)\end{array}$} & \multicolumn{1}{|c|}{$\begin{array}{c}\text { Terceira Fase } \\
(1978-2000)\end{array}$} \\
\hline $\begin{array}{l}\text { Como concebiam } \\
\text { o fenômeno da } \\
\text { mestiçagem }\end{array}$ & $\begin{array}{l}\text { De maneira positiva } \\
\text { (discurso pró- } \\
\text { mestiçagem) }\end{array}$ & $\begin{array}{l}\text { De maneira positiva } \\
\text { (discurso pró- } \\
\text { mestiçagem) }\end{array}$ & $\begin{array}{l}\text { De maneira negativa } \\
\text { (discurso contra a } \\
\text { mestiçagem) }\end{array}$ \\
\hline $\begin{array}{l}\text { Dia de reflexão e/ou } \\
\text { protesto }\end{array}$ & $\begin{array}{l}\text { 13 de Maio (dia da } \\
\text { assinatura da Lei } \\
\text { Áurea, em 1888) }\end{array}$ & $\begin{array}{l}\text { 13 de Maio (dia da } \\
\text { assinatura da Lei } \\
\text { Áurea, em 1888) }\end{array}$ & $\begin{array}{l}\text { 20 de Novembro (dia } \\
\text { de rememoração da } \\
\text { morte de Zumbi dos } \\
\text { Palmares) }\end{array}$ \\
\hline Principais lideranças & $\begin{array}{l}\text { Vicente Ferreira, } \\
\text { José Correia Leite, } \\
\text { Arlindo Veiga dos } \\
\text { Santos }\end{array}$ & $\begin{array}{l}\text { José Bernardo da } \\
\text { Silva, Abdias do } \\
\text { Nascimento }\end{array}$ & $\begin{array}{l}\text { Hamilton Cardoso, } \\
\text { Lélia Gonzalez }\end{array}$ \\
\hline
\end{tabular}

Este quadro é uma avaliação um tanto ou quanto esquemática da trajetória do movimento negro no período republicano. Evidentemente, a evolução histórica desse movimento não foi estanque ou linear; ao contrário, foi marcada por contradições, avanços, recuos e estagnações de diversas ordens. Alguns militantes, inclusive, atuaram ativamente em mais de uma fase. Todavia, para fins analíticos, buscaram-se apontar as linhas gerais que caracterizaram a ideologia, a dinâmica interna, a atuação política, os métodos de luta, o discurso, em suma, alguns elementos da vida orgânica daquele movimento. Trata-se, na verdade, de uma tentativa de sinalizar as principais tendências que nortearam a luta anti-racista no país.

\section{Quarta fase do Movimento Negro organizado na República (2000 - ?): uma hipótese interpretativa}

Alguns elementos sinalizam que no início do terceiro milênio está se abrindo uma nova fase do movimento negro, com a entrada em cena do movimento hip-hop, por vários motivos. Trata-se de um movimento cultural inovador, o qual vem adquirindo uma crescente dimensão nacional; é um movimento popular, que fala a linguagem da periferia, rompendo com o discurso vanguardista das entidades negras tradicionais. Além disso, o hip-hop expressa a rebeldia da juventude afro-descendente, tendendo a modificar o perfil dos ativistas do movimento negro; seus adeptos procuram resgatar a auto-estima do negro, com campanhas do tipo: Negro Sim!, Negro 100\%, bem como difundem o estilo sonoro rap, música cujas letras de protesto combinam denúncia racial e social, costurando, assim, a aliança do protagonismo negro 
com outros setores marginalizados da sociedade. E para se diferenciar do movimento negro tradicional, seus adeptos estão, cada vez mais, substituindo o uso do termo negro pelo preto. ${ }^{52}$

Apesar de estar em curso um processo de transição nas formas de engajamento e luta anti-racista no país, é precoce decretar que a agitação do hip-hop sela uma ruptura na plataforma do movimento negro. Primeiro, porque ele ainda é um movimento desprovido de um programa político e ideológico mais geral de combate ao racismo. Segundo, porque o hip-hop no Brasil não tem um recorte estritamente racial, ou seja, não visa defender apenas os interesses dos negros. Daí o discurso ambivalente. Se, de um lado, esse movimento tem um discurso radicalizado de rebeldia contra o sistema (termo sempre usado de maneira abstrata!), de outro, não define explicitamente qual é o eixo central da luta. Desde que chegou ao país, o hip-hop adquiriu um caráter social. Embora seja esposado pelos negros, ele também tem penetração nos setores da juventude branca marginalizada que vive na periferia dos principais centros urbanos do país.

\section{Considerações finais}

Com a extinção da escravidão, em 1888, e a proclamação da República, em 1889, a elite brasileira implementou políticas públicas alicerçadas nos postulados do "racismo científico e do darwinismo social e lançou o Brasil numa campanha nacional (...) para substituir a população mestiça brasileira por uma população 'branqueada' e 'fortalecida' por imigrantes europeus". ${ }^{53}$ Os egressos do cativeiro e os afro-descendentes de um modo geral foram privados - ou tiveram dificuldades - de acesso ao emprego, à moradia, à educação, à saúde pública, à participação política, enfim, ao exercício pleno da cidadania. Ante tal situação, uma parte deles não permaneceu passiva. Pelo contrário, levou avante múltiplas formas de protesto, impulsionando os movimentos de mobilização racial (negra) no Brasil. Foram engendradas diversas organizações com base na identidade racial; elas procuravam projetar os "homens de cor", como atores políticos, no cenário urbano. ${ }^{54}$

\footnotetext{
${ }^{22} \mathrm{O}$ termo preto, difundido pelos adeptos do hip-hop, é a adoção traduzida do black, palavra utilizada por décadas pelo movimento negro estadunidense. Já a rejeição que eles fazem do negro deve-se ao fato de que nos Estados Unidos esta palavra origina-se de niger, termo que lá tem um sentido pejorativo.

${ }^{53}$ G. R. Andrews, O protesto político negro..., op. cit., p. 32.

${ }^{54}$ Luiz Alberto de Oliveira Gonçalves, "Os movimentos negros no Brasil: construindo atores sociopolíticos”, Revista Brasileira de Educação, n. 9, São Paulo, 1998, p. 33.
} 
Já na primeira fase do movimento negro na era republicana (1889-1937), emergiram organizações de perfis distintos: clubes, grêmios literários, centros cívicos, associações beneficentes, grupos "dramáticos", jornais e entidades políticas, as quais desenvolviam atividades de caráter social, educacional, cultural e desportiva, por meio do jornalismo, teatro, música, dança e lazer ou mesmo empreendendo ações de assistência e beneficência. Em momento de maior maturidade, o movimento negro se transformou em movimento de massa, por meio da Frente Negra Brasileira. Na segunda fase (1945-1964), o Movimento Negro retomou a atuação no campo político, educacional e cultural. Com a União dos Homens de Cor e o Teatro Experimental do Negro, passou-se a enfatizar a luta pela conquista dos direitos civis. Na terceira fase (1978-2000) surgiram dezenas, centenas de entidades negras, sendo a maior delas o Movimento Negro Unificado.

Nas duas primeiras fases, a maior parte do movimento negro mantémse afastado das formas tradicionais de organização das classes sociais (a saber: sindicatos e partidos). Isto não significa que o movimento tenha ficado em estado de isolamento político, haja vista que alguns de seus setores contraíram alianças e assumiram compromissos com diversas forças políticas e ideológicas. Na terceira fase, entretanto, boa parte do movimento negro se aproxima dos partidos e dos sindicatos, procurando estabelecer um liame nas ações de natureza classista e anti-racista.

Ao examinar o discurso das lideranças negras em uma perspectiva histórica, percebe-se uma pluralidade de incursões político-ideológicas, desde a defesa de teses autoritárias até a apologia de proposições socialistas. Se, nas duas primeiras fases, o movimento negro organizado tem majoritariamente posições políticas de "direita", na terceira fase ele se alinha à "esquerda" marxista e preconiza um programa em prol da justiça racial que sensibiliza cada vez mais a sociedade brasileira.

Em 1985, o historiador brasilianista Thomas Skidmore escreveu: "Não há história geral dos movimentos negros e/ou mulatos no Brasil moderno, fora da época abolicionista. Isto não é surpreendente, já que pouca pesquisa se fez a respeito". ${ }^{55}$ Skidmore tinha razão: movimento negro era um tema pouco explorado pela historiografia brasileira na década de 1980. Hodierno, esse panorama vem se alterando, sem contudo deixar de suscitar algumas peculiaridades. Muitas das pesquisas sobre o movimento negro ainda não foram

${ }_{55}$ T. Skidmore, O Brasil visto..., op. cit., p. 148. 
publicadas; elas são encontradas na forma de dissertações e teses acadêmicas, o que dificulta a divulgação em circuitos de maior alcance. Outra peculiaridade é que as organizações negras de São Paulo e do Rio de Janeiro têm sido as mais estudadas até o presente. Estes estudos produzem um quadro apenas parcial, visto que houve (e há) organizações negras estruturadas e atuantes nas cinco regiões do país.

É comum pensar que o movimento negro organizado só começa nos anos 1930 - por meio da Frente Negra Brasileira -, sendo retomado décadas depois, com o florescimento do Movimento Negro Unificado, no final dos anos 1970. Este artigo corrobora para refutar essa visão. Ou seja, havia uma articulação de atores e grupos negros em outros momentos. Isto permite afirmar que o movimento negro contemporâneo já acumula experiência de gerações, sendo herdeiro de uma tradição de luta que atravessa praticamente todo o período republicano.

É por intermédio das múltiplas modalidades de protesto e mobilização que o movimento negro vem dialogando, não apenas com o Estado, mas principalmente com a sociedade brasileira. ${ }^{56}$ A trajetória desse movimento vem se caracterizando pelo dinamismo, pela elaboração e reelaboração, em cada conjuntura histórica, de diversas estratégias de luta a favor da integração do negro e erradicação do racismo na sociedade brasileira. Para finalizar, vale lembrar que o movimento negro forjou um certo nível de organização no pósAbolição que não pode ser mais obliterado pela historiografia e, especialmente, pelas linhas de pesquisas especializadas no resgate dos movimentos sociais do período republicano.

\footnotetext{
${ }^{56}$ Apesar das dificuldades, o movimento negro tem se consolidado como ator político no cenário nacional. E "não se trata de romantizar a experiência desse movimento social", argumenta Barcelos, "mas de contextualizá-la”. Cf. Luiz Cláudio Barcelos, "Mobilização racial no Brasil: uma revisão crítica”, Afro-Ásia, n. 17, Salvador, 1996, p. 209.
} 